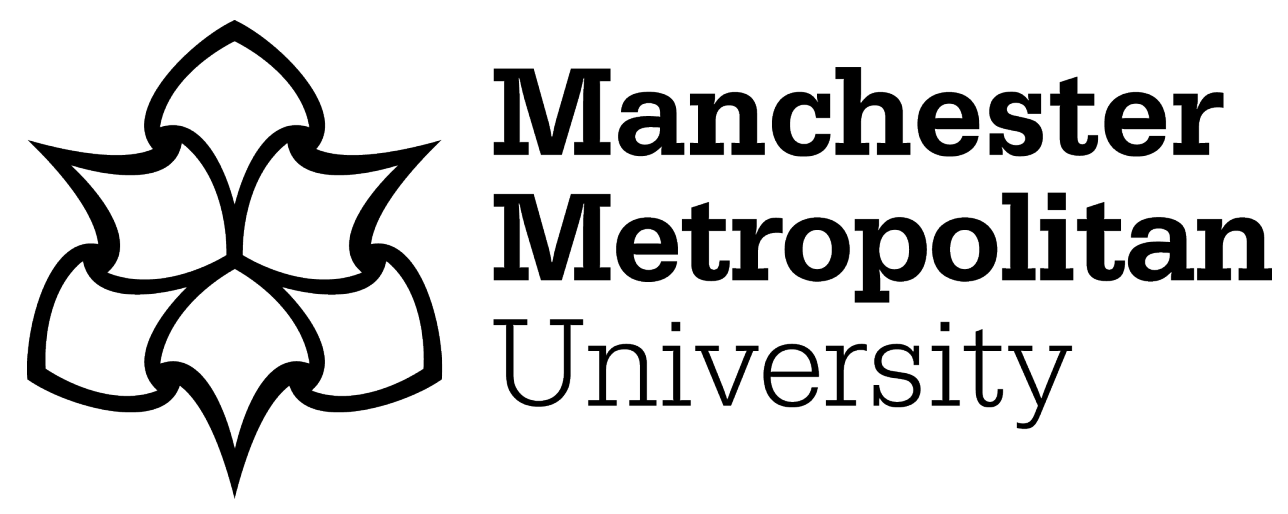

Grix, J and Harris, S (2016) Governance and Governmentality of Sport. In: Routledge Handbook of Sport and Politics. Routledge International Handbooks . Routledge, pp. 3-15. ISBN 9781317646679

Downloaded from: https://e-space.mmu.ac.uk/621305/

Version: Accepted Version

Publisher: Routledge

DOI: https://doi.org/10.4324/9781315761930

Please cite the published version 


\section{Governance and Governmentality of Sport}

Jonathan Grix and Spencer Harris

\section{Introduction}

A number of issues have ensured the rise in prominence of the term 'governance' in relation to sport in recent years. First, a series of scandals have taken place associated with the governance of sporting structures commonly referred to as management corruption (e.g. FIFA), Second, a series of problems associated with competition in sport commonly referred to as competition corruption (e.g. doping in sport). Third, governments globally appear to be increasingly intervening in sport policy for non-sporting - and mostly political - ends. Finally, scholars have grappled with the term in order to explain a change in the manner in which public policy is delivered in a number of advanced democracies. 'Governance', as a concept, has started to be used in sports studies to understand sport more often since the early 2000s. This is despite the fact that sports studies is relatively slow at taking on concepts from 'main' academic disciplines, as the trajectory of the core terms from sociology, 'social capital', and from international relations, 'soft power', show. The rise to prominence of 'governance' followed the development in most advanced capitalist states and many 'emerging' of a mixture of New Public Management - that is, a 'devolved' central power and a desire to deliver public policy more efficiently. New Public Management appears to be an almost universally accepted governance type that is ideologically-driven, purports to allow policy practitioners autonomy from a centralized state, while 'steering' from behind the scenes.

Sport governance takes place at many levels, perhaps most clearly at the domestic and the international level of governance. The former concerns itself with how sport policy is delivered, how sport is funded and which type of organisations make up the so-called 'sportscape', including National Sport Organisations (NSOs). International governance of sport concerns itself with those organisations that are responsible for trans-national sport, for example, the 
World Anti-Doping Agency, the International Association of Athletics Federations (IAAF), FIFA (Federation Internationale de Football Association) and the IOC (International Olympic Committee). Such global organisations set the context within which NSOs operate; decisions made at a supra-national level often impact on and directly affect NGBs and their policies. The governance of sport is, therefore, not just a matter for individual nations. Key actors in world politics, for example, the United Nations (UN), and increasingly the European Union (EU) and the Council of Europe, have a direct impact on national sport. An example of agenda setting policy at supra-national level is the European Commission's 2007 White Paper on sport, which suggests member states ought to encourage a greater role for equal opportunities in sport. This is likely, in time, to force traditionally gendered sports such as golf to change their archaic policies and practices. The focus in this chapter, is, however, on the domestic or national level of governance and we do so by arguing that the so-called 'governance narrative', outlining a shift from big, central government to devolved 'governance' of policy, does not hold for the sport policy community. Further, we propose that fusing insights from the literature on 'governance' together with those from 'governmenality' - can be fruitfully used to shed light on understanding the sport policy community. This offers a new analytical framework to assess the governance context in which the policy process evolves rather than a specific approach to policy analysis. The chapter unfolds as follows: after an overview of the 'governance' debate we introduce a 'new governmentality' approach, we then set out the community sport policy context before analysing community sport from a new governmentality perspective.

\section{Governance and the 'governance narrative'}

Issues around 'governance' have become increasingly important in the last 30 years, as sport has become more politicised and as governments have invested more into sport. With heavy financial investment comes strict accountability and the need to modernise often archaic practices. In the world of sport this has led to a number of key tensions, for sport in many countries has been - and still is to a large extent - run by amateur volunteers. The delivery of 
sport policy in the majority of advanced capitalist states or advanced liberal democracies runs from government departments via NSOs (in the US the Olympic Organisation distributes monies to NSOs). It is clear to see how increasing levels of government funding and interest can give rise to difficulties in sport policy delivery: as modern, technocratic modes of governance meet archaic, amateur sport structures there is bound to be friction. Two strands of literature are of interest in understanding the manner in which sport is governed at the domestic level: the socalled 'governance narrative' literature and Foucault's ideas about power encapsulated in the concept of 'governmentality'. Why this is of interest to sport politics is also clear: the domestic governance of sport covers key issues such as the funding for NSOs (who gets what, when and how), the mechanisms developed to monitor them (the checks and balances) and the effects such systems have on long-term sport development.

Only recently has sports studies looked to the mature debates in political science and public administration concerning the state's changing role in the delivery of public policy. Yet, the socalled 'governance narrative', slowly becoming the new orthodoxy in political science (Marsh 2008a), is more often than not presented as the key approach to understanding recent developments in public policy in leading text books on the subject (see Coxall, Robins and Leach 2003, Dorey, 2005, Hill, 2009). The 'governance narrative' is a broad-brush approach that can usefully assist in 'framing' particular studies of the sport policy area, ranging from those dealing with issues of meta-governance down to studies involving street-level bureaucrats, or both. The focus of the original work on 'governance' was the 'Westminster style' of Government (for example, Australia, Canada and New Zealand), but general principles hold for the majority of advanced capitalist states investing heavily into sport. In particular, how governments fund elite sport, the mechanisms in place to make sports organisations accountable for the funds they receive and the criteria and ideology upon which such a system rests. 
In a nutshell, the 'governance narrative' suggests a major shift in politics and public policy from 'big' Government to governance through networks, a wide array of 'partnerships' and devolved bodies, thereby bringing policy closer to the street level and thus society. 'Partnership' working in particular, especially in sport policy delivery, has been championed strongly. This shift has led to the erosion of central Governmental power and with it, the state's ability to determine and deliver policy (Bevir and Rhodes 2006; 2008, Skelcher 2000). The diffusion of power moves from an hierarchical, top-down delivery of policy, to one that is side-ways, with governance through a series of networks in which a wide variety of interests are represented.

The application of this approach to public policy in the UK has been critiqued for not capturing how the sport policy sector is governed. In particular Goodwin and Grix (2011) and Grix and Phillpots (2011) have shown that sport policy (and a number of other sectors) is a 'deviant' case and as such does not fit this ideal type. This leads to a number of very interesting questions that shed light on the most salient aspects of the discussion around domestic governance. For example, why does sport policy (and others) not fit the notion of devolved, dispersed power among a variety of actors with increased autonomy from the central executive? After all, there is clearly a trend to 'agencification' in the sport policy area, including arm's length agencies, the rapid growth of 'partnerships', networks, charities, advisory bodies, boards, commissions, councils and other non-governmental bodies. The process described by the 'governance narrative' does not result in a 'hollowing out' of the state, but, perhaps paradoxically, rather in an increased capacity for central state control in most mature democracies (see Taylor 2000). The underlying, hierarchical power relations and resource-dependence between networks, partnerships and Government remain intact. The paradox arises between surface observation (the growth of devolved bodies) and the underlying power relations of networks and partnerships involved in policy making and delivery. And this surface observation is usually enough evidence to confirm a shift from big, interventionist 'government' to more autonomous governance by networks and partnerships (Bevir and Rhodes 2008, Marsh 2008b), a central tenet 
of the 'governance narrative'. Therefore, the 'governance narrative' ideal type does not account for the continuance of 'asymmetrical network governance' (Goodwin and Grix 2010) between Government and resource-dependent actors, which exist in both elite and grass-roots policy delivery in the UK (see Newman 2005, for a critique of elements of the 'governance narrative'). This is an important point and one that has wider significance beyond the UK case. As discussed below, such an understanding of 'governance' - whereby 'devolved' bodies of public policy delivery do not lead to more open, democratic processes, but can be read as a state strategy for control - touches on many of the areas central to Foucault's notion of 'governmentality'.

On the surface the 'governance narrative' would appear to correctly characterise the sport policy sector in the UK. There is no doubt that there is a multitude of organisations, committees and charities involved in sport delivery resulting in one of the most 'divided, confused and conflictive policy communities in British Politics' (Roche, 1993, 78) for this very reason. There are a bewildering array of actors - many with overlapping and unspecified roles - involved in the delivery of sport policy, including non-departmental public bodies (for example, the funding agencies for grass roots and elite sport, Sport England and UK Sport), a Sports Minister, an Olympics Minister, a UK Sports Institute, the British Olympic Association, 46 NSOs, 49 County Sport Partnerships and Local Authorities all working in one way or another together with the Government Department, DCMS (Department of Culture, Media and Sport) to deliver sportrelated services. This is further complicated by the fact that there are private actors, charities, not-for-profit organisations, government-near bodies and so on making up the sportscape. However, inherent in this system - depending on how wealthy the NSOs are - are asymmetrical power relationships, mostly driven by dependency on central government resource. This ties in neatly with discussions around 'governmentality'.

Foucault put forward this term - which he coined 'the art of government' (1991) - as a way of capturing how governments manage to exert power over subjects by using techniques to ensure 
individuals govern themselves, but in line with the government's aims and objectives. That is, there is no overt use of force, but 'Increasingly, government seeks not to govern per se, but to promote individual and institutional conduct that is consistent with government objectives' (Raco and Imrie, 2000, 2191). The manner in which this is carried out by governments is to offer autonomy, but with strings attached (Piggen et. al., 2009, 89). And this is where sport policy comes in. The UK, Australia, Canada and New Zealand, to name but a few states, have introduced 'modernisation' programmes to public policy delivery 'designed (ostensibly) to empower and autonomize NSOs' (Green and Houlihan, 2006, 49). This has been accompanied, however, by a growing regime of centrally-set targets, directives and sanctions (Grix, 2009). Sam (2009, 505) has found similar tendencies in New Zealand sport and states that through 'modernisation':

....traditional, volunteer 'kitchen table' administration is meant to be replaced with more formalized operations and an adherence to established management practices such as strategic planning, and the use of key performance indicators in monitoring and evaluations.

\section{New governmentality}

Our conceptualization of new governmentality combines key elements from the governance narrative and governmentality. Specifically, we are interested in the macro context presented by the governance narrative. Policy agents today operate in an increasingly open, democratic and autonomous policy community. We also highlight the possibility that the ideals of a democratic and 'newly' empowered policy community represent little more than the state's most recent strategy to retain control. In this respect, the process of governmentality reveals the art of government, the way in which governing authorities manage the conduct of individuals and groups: 'to govern, in this sense, is to control the possible field of actions of others' (Foucault, 2002, 341 in Bulley \& Sokhi-Bulley, 2014). Thus, new governmentality can be described as an intentional government strategy which promotes the ideals of shifted power from central 
government to networked-agents whilst using a range of tactics to retain control and to ensure that conduct is aligned with government objectives (Rose, 1999).

Examples of new governmentality in England include such things as the Localism Act, the ostensible aspiration to move decision-making power and resources from central Government to local communities. At the same time government maintain control by requiring that communities fulfil financial conditions and engage with ongoing performance management requirements. Alternatively, the key tenets of the 'Big Society' reflect the essence of the governance narrative. The Big Society can best be described as a major programme of modernization, a model representing a slimmer, more efficient government focused on engaging society, promoting social responsibility, actively encouraging community control and self-management (Bulley \& Sokhi-Bulley, 2014), and re-energising people power as the key solution to a broken society (Cameron, 2009). These highly vaunted virtues reflect the key attributes of the governance narrative, not least the step away from the traditional, hierarchical Westminster mode of governance and the step toward a new democratic order. However, further examination reveals 'the government as a series of tactics for managing conduct, as a mentality, ... to spread responsibility as one of disseminating and diffusing the exercise of power as government' (Bulley \& Sokhi-Bulley, 2014: 465). In other words, government continue to govern; they just do so through the use of new and re-invented forms of control.

Before turning to an example of how a 'new governmentality' approach could shed light on sport policy in the UK, it is important to stress how our conceptualisation differs from the original, post-modernist perspective. This is best explained in reference to our starting point, in fact, the starting point of all research, whether one likes it or not: that is, the ontological and epistemological position in which our new conceptualisation is grounded (see Marsh and Furlong, 2002). We have argued at length elsewhere that researchers ought to be explicit about their 'worldviews' (a 'lay' way of summing up a researcher's meta-theoretical position) as this 
obviously informs the questions they ask, the methods they draw upon to answer those questions and the theoretical frameworks they use to shed light on social phenomena (Authors, 2002; 2010a). The roots of our conceptualisation of 'new governmentality' are to be found 'on the border' between the research paradigms of 'interpretivism' and 'critical realism' and thus allows for an understanding of this new type of governance that seeks to take into account both actors' beliefs and ideas, but also leave room for structures and institutions in any explanation; such a perspective we term 'hard interpretivism' (see authors, 2010b for a much more thorough discussion).

\section{New governmentality in community sport in England}

While sport policy in the UK is not a new phenomenon, the way in which it is presented, governed and delivered has changed considerably over the past 15 years. Relatively broad statements concerning indoor sports facilities, playing fields, school sport, inequality in sport and talent development have been replaced with precisely defined objectives, time-bound targets, and a relatively sophisticated (and, in some cases, costly) means of measurement. This is not to argue that all policy is presented this way or that this new form of public presentation is a prerequisite for all policy. Clearly, policy comes in many forms. That said, the key sport policy priorities of the central government since 2008, school sport, community sport and elite sport have undoubtedly been subject to greater precision. This is due to three factors: (i) the increasing interest in sport at the highest political levels (Houlihan and Green, 2012); (ii) the considerable growth in the public monies (exchequer and lottery funding) allocated to sport, and (iii) the broader influence of Government attempts to modernize public services and its commitment to New Managerialism involving the application of commercial sector ideas and practices to the public sphere (Green, 2009; Grix, 2009). 
Community sport policy in England is led by Sport England under the direction of the Department of Culture, Media and Sport ${ }^{1}$. There are a number of policy directives that guide the work of Sport England encompassing such matters as: supporting volunteers, encouraging talent, promoting public value (not private gain), involving the community in decision making, and equally distributing funding across England (DCMS, 2015). Central to these directives is the core policy for the period 2012-2017: a year-on-year increase in the proportion of people who play sport once a week for at least 30 minutes and, in particular, an increase in the percentage of 14 to 25 year olds playing sport once a week, and a reduction in the proportion of 14 to 25 year-olds dropping out of sport. Implementation is led by National Governing Bodies of Sport (NGBs) with support from County Sport Partnerships and a range of national agencies including Street Games, Dame Kelly Holmes Legacy Trust, Sports Coach UK, Youth Sport Trust, English Federation of Disability Sport, Sporting Equals and the Women's Sports Foundation (see Figure 1). The specific action plans, programmes, and targets for increased participation reside within the Whole Sport Plan of each NGB. These plans are assessed by Sport England and funding allocations are awarded to each NGB based on goals and targets as well as the growth potential of each sport. For the period 2008-2017, a total of $£, 950$ million was invested in NGB whole sport plans and the support services of County Sports Partnerships (Sport England, 2015). The NGB-CSP partnership represents the institutional delivery arm of community sport policy insomuch as it is responsible for translating the NGB whole sport plan into local-level action (activities, programmes, promotional campaigns, etc.). In this way the CSP is considered the strategic lead agency for sport for the sub-region and thus best placed to support the NGB in the implementation of its Whole Sport Plan. Measuring progress against the policy objective is achieved through the Active People Survey. This survey collects a range of information about frequency and type of sports participation and allows analysis of changes in sports participation across the England population from 2005/6 to the present day.

\footnotetext{
1 Each of the home country Sports Councils (Wales, Scotland, Northern Ireland and England) has lead responsibility for community sports policy in their respective country.
} 
Figure 1 here

The community sport policy process is an interesting case study when examining governance in England. On the one hand, the community sport landscape-that is, the range of agencies and partnerships that make up the delivery system for community sport-appear to present an apposite example of the governance narrative, in particular the creation of ostensible democratic network structures and the apparent shift of power from central government to local communities. However, these structural arrangements reveal significant power imbalances across the various agencies (Grix, 2010). At the same time, against the broader governmental policy context of Localism, Big Society and power devolved to networks, NGBs and CSPs must respond to the various strategies of government that have been designed to influence, manage or control policy delivery (Harris, 2013). In particular, we draw attention to three examples of strategies that reflect new governmentality: the structure of the community sport system, the Whole Sport Plan process, and the performance management system. These examples are drawn from empirical work focusing on the beliefs and ideas of actors within the networks themselves, specifically senior managers of NGBs, CEOs and board members of CSPs, and senior managers of local authorities.

\section{The structure of the community sport system}

The rhetoric relating to the community sport delivery system suggests a simplified, focused and democratic partnership combining sport and local community interests. On the surface the networked partnerships ${ }^{2}$ 'signify equalities of power, shared values and the establishment of common agendas and goals' (Newman, 2005, 81) together with the provision of skills, expertise and financial resource-coordinated at the street-level—-to drive growth in community sports participation. In reality, the community sport policy community reflects the Weberian notion of

\footnotetext{
${ }^{2}$ We refer to these networks as networked partnerships as they bring together a range of existing sport-based partnerships (e.g. NGBs, county sports associations, clubs, etc.) and community-based partnerships (e.g. County Sports Partnerships, local authorities, Clinical Commissioning Groups, etc.) into a broader network focused primarily on community sport.
} 
bureaucratic rationality, a top-down policy led by a narrow coalition made up primarily of government departments and NDPBs (e.g. Sport England) on down to NGBs.

We have a very heavy top-down system ... that is all well and good, but if you don't know what is going on at the local level, who has agreed to do what, what is working and what is not, you're not likely to be very successful (Principal Sports \& Recreation Manager, Metropolitan Borough Council).

The experience of the last four years has shown that most NGB strategies were top-down, were focused on the national level, and most did not know what they wanted to do at the local level. You could go and sit down and have a meeting with them and they would not be able to articulate their priorities for [the area] or how they wanted us to help them (Operations Manager, CSP)

Indeed, research into the community sport policy process underscores a top-down policy subsystem characterised by its hierarchy and consequent divisions (Harris, 2013). The hierarchy or patterns of authority across the policy subsystem reflect the resource dependency of the agencies that make up the system. Thus, the authority of 'the principal' cascades down the community sport structure whereby the various 'principals' (the principal varies according to level) attempts to control and manage the behaviour of various 'agents'. To clarify, at the national level, the capacity and authority of the national-level agent (Sport England) is heavily dependent on the resources it receives from the principal (DCMS). Similarly, the ability of NGBs (agents) to secure funding for growing and sustaining sports participation is dependent on the resources it receives from the principal (Sport England). This pattern of authority and dependence cascades down the community sport structure and influences the nature of the relationships between NGBs, CSPs, local authorities and community sports clubs. Thus, from a rational perspective, it is in the agents' interest to cooperate and support the principal or governing authority, and reflect their ideals and norms, rather than bargain or enter into conflict regarding the nature of community sport policy. This is not to imply that agents unquestionably comply with principal requirements and refrain from subverting policy demands, but the hierarchical structure and the systems established to support principal control do reinforce the 
more centralised, traditional Westminster model of governance, as opposed to a shift of power to the local-level.

The notion of democratic governance belies the nature of the enforced partnership between NGBs and CSPs and creates significant structural problems that hinder cooperation and collaboration across the community sport landscape. The partnership is described as enforced, as agencies, in particular CSPs, must comply with the minimum standards set out in Sport England's core specification in order to receive funding. While the networked partnership between NGBs and CSPs may work well in isolated cases there are fundamental flaws in the structure, not least in the extent to which partners cooperate and engage with one another, and the degree to which there is consensus on the leadership role of NGBs and CSPs. The problem of engagement primarily relates to the broader conception of the CSP and its role in the strategic leadership of sport across the sub-region. When CSPs were created in the early 2000s, one of their core functions was to provide leadership and coordination for sport across their area. CSPs were conceived as broader partnerships, umbrella organisations that would represent local authorities, county sport associations and others involved in sport. The CSP would be the voice for sport for the area, the lead agency responsible for enhancing communication and coordinating efforts to grow sports participation and enhance talent. Whilst this broader conception of the partnership remains a feature of CSPs, to fulfill their role effectively, two conditions must be met. First, the CSP must develop and pursue a strategic role. Second, it must be viewed and sanctioned as the strategic lead for sport by the agencies. Unfortunately, community sport appears to have a structure where, in some counties, the CSP assumes the former without the latter having taken place. For example: 'first and foremost we are a strategic agency' (Director, CSP); 'we have got to be seen in our area as taking the lead, we manage programmes and utilise local authorities and community networks to deliver' (NGB Lead Officer, CSP). In contrast, NGBs and local authorities reveal a range of perspectives, which underscore their independence and resistance to leadership from an outside source. Indeed, 
rather than representing a collective approach in which the CSP and local authorities work handin-hand, the local authority perspectives illustrate a more complex and, at times, divisive relationship where they feel that the CSP are attempting to take a lead role or dictate strategic and operational matters, where the local authority themselves felt better placed to do so:

The CSP talks about being the strategic lead, strategic lead this, strategic lead that...but actually, strategic leadership comes at the local level...there is an argument that there is no need for CSPs. If NGBs worked more effectively with local authorities there would be more resources available to coordinate programmes in order to sustain and grow participation (Sports Development Manager).

Adding to this, other local authority representatives stressed the local community development role of municipalities and their traditional role in facilitating sport development as a potential cause of tension and general lack of enthusiasm for the partnership:

I don't think we actually need the CSP...we could do the work ourselves if we had the funding. I would argue that we are better placed because we have the local links to make these things sustainable, we have the local knowledge and understanding to make sure it is needs-based and being delivered where it should be delivered, and to make sure that it is clearly coordinated with other services and programmes (Community Development Manager, City Council).

The credibility of the partnership is further weakened by some NGBs who claim that the CSP's role in community sport is overstated: 'If I'm honest, I don't spend a lot of hours with them through the year, it's not a priority, my priorities are schools and clubs, and places to play' (Regional Development Manager, Lawn Tennis Association); 'while I'm mindful of the core funding that CSPs receive, it is difficult to drill down to clearly see what value and support the CSP can offer' (Regional Development Manager, Amateur Swimming Association). This reinforces the view from local authorities concerning the lack of consensus regarding the place of the CSP as the strategic lead for sport for the sub-region and underscores the pervasive nature of power and the way in which this intersects with seemingly rational and positive attempts to 
create strategic leadership for sport at the sub-regional level:

[A] lot of it is about the CSP wanting to be seen as the gatekeeper of sport in the area, but they're not necessarily seen as this. I mean, we would rather do the work ourselves than rely on a gatekeeper (County Director, England \& Wales Cricket Board).

Thus, while the CSP may represent a partnership in name, the original, government-driven, broad conception of the partnership to provide a strategic lead and a voice for sport for the subregion encompassing local authorities, county sport associations and others has not yet transpired. Rather than aiding policy implementation, the deep structures of power underpinning the partnership will more likely make the exercise of achieving policy goals more challenging than it otherwise might be (Bloyce et al., 2008).

\section{The Whole Sport Plan process}

Despite the limited role of NGBs and CSPs in the formulation of national policy, NGBs play a significant role at the next level down, where they translate policy for their sport through their Whole Sport Plan. This sets out the 'community sport policy' for each NGB, detailing the targets and how the targets will be achieved. These plans are then assessed by Sport England and funding allocations agreed based on the details of the plan and the growth potential of each sport. Clearly, in the context of open and democratic governance, there is an opportunity for NGBs to engage key stakeholders in the formulation of its plan. However, the majority of NGBs reportedly pursued an insular approach, led by the upper echelons of the organisation. This is despite Sport England facilitating a series of roadshows with the aim of improving stakeholder engagement in the NGB whole sport planning process, an exercise which was largely viewed as being superficial, designed to create the illusion of engagement and consultation while allowing NGBs to continue their insular approach to planning. On reflection, this approach reinforces three key problems. First, it compromises the basic premise of network governance, that is, interacting with stakeholders on important decisions, and fails to secure commitment and 
consensus from implementing agents (such as local authorities, clubs, Universities, schools, etc.). Second, it limits the insight of the NGB to a partial view of the broad context affecting policy, therefore remaining ignorant of significant issues that will inhibit policy implementation (Marsh \& Smith, 2000). Third, it illuminates the power imbalance across different levels of the community sport system, particularly between national-level NGBs, county sport partnerships, county sport associations, local authorities and local voluntary sports clubs. As one sport representative explained, making reference to the collapse of the British Athletics Federation and the creation of UK Athletics, 'even in the bad old days there was more democratic decision making, more sense of ownership of the sport than there is today' (Chairman, County Athletics Association). Others reiterated the sentiment: 'one of the big problems is that NGBs devise their own plans and programmes and become very attached to them without involving local partners' (Director, CSP); 'the problem with many NGBs is that they don't even try ... I mean why not come and talk to us? We know what is best for the local area, we represent it' (Head of Culture \& Sport, County Council). Such comments not only underline the power imbalance inherent within the system but also the alienation that such behaviour cultivates. This, in turn, creates and perpetuates a 'them and us' culture, and at its extreme, creates an apathetic or hostile environment where street- level workers seek to modify or subvert policy because it is unclear or fails to relate to the local context within which they operate (Barrett \& Fudge, 1981; Lipsky, 1980). In sum, whilst the autocratic or insular approach of NGBs may offer a relatively quick and efficient means of translating policy, it does little to secure the participatory consensus of grassroots implementers and is likely to be far more effective in pushing partners apart rather than galvanizing collective effort and collaborative capacity. Furthermore, it clearly fails to reflect the simplified and clearly coordinated system of delivery promoted by Sport England.

The core specification, the core funding agreement and the performance management system

In 2008 , as a result of the revised strategy and structure for community sport, Sport England created a series of tools to strengthen the governance and accountability of the community sport 
system. These tools included the core specification, the core funding agreement, the performance management system and the payment by results scheme. These tools are pertinent examples of the techniques of modern managerialism (Newman, 2005). However, they also epitomize the tactics of a govern/mentality (Barron, 2005, 984) - the processes of governanceconcerned with shaping, guiding and directing the conduct of agencies and individuals (Gordon, 1991). While the resource dependency of most community sport agencies means that they conform with such requirements, they do so whilst reporting that such techniques adversely affect the bigger picture, namely cultivating the NGB-CSP relationship and focusing on participation growth. The core specification, core funding and performance management system were seen to be useful in some regards, particularly in relation to focusing attention, setting out expectations, minimum requirements and contractual obligations. However, such principles, specifically the creation of specifications and contracts, could be argued to contradict the very notion of network governance. Moreover, from an agents' perspective the overt emphasis on and demands of such processes was seen to unbalance the task-people management orientation of the NGB-CSP relationship toward a wholly task-orientation, which in turn was generally viewed to be a major step back to the task-heavy days of an outdated public sector, stifling the softer skills and attention needed to broker and enhance partnerships and partnership interactions:

Sport England has all those documents like the core specification that we as a CSP have to use, but they are just pieces of paper. What is more interesting for us is the people behind the plan. The papers sit on the shelf, it's about getting beyond that to actually make it happen. We need to focus more on the relationship and how we can work together to achieve our goals (NGB Lead Officer, CSP).

I guess the final thing to say is about the target mentality that we all work in now. On the one hand it's fine, we need direction, we need it to help prioritise ... The core specification is a little like that, okay, this is what I need to do, what I need to offer to be seen in a good light. But partnership working needs to be more genuine, it needs to go beyond this, it requires a more open conversation about vision, priorities and roles and responsibilities (Chair/Trustee, CSP). 
Alongside this, the quarterly performance management system was seen to reinforce a shortterm view where the priority was to turn in a 'good report'. A good report reflects good or outstanding performance in a range of specific tasks. The problem here is that many of the tasks included in the performance review do not naturally align with or contribute to growth in sports participation. For example, a CSP could submit quarterly performance reports over a four-year period that were judged to reflect outstanding organizational performance, yet at the same time the CSP could witness significant decreases in sports participation in the county. Thus, the process drives behaviours, such as focusing attention and allocating resources to achieving shortterm goals, such as achieving 'excellent' performance reports, rather than the more challenging, longer-term goal of driving growth in mass participation. Simultaneously, the process emphasizes recognition and rewards for outstanding performance and high achievement as determined by the information provided in the performance report. This approach, what Demming (2000) referred to as the 'deadly disease of management', encourages agencies to do whatever is necessary to present themselves in the best possible light and reinforces an approach whereby 'perception rules substance or reality'.

We have to be honest about what is working and what is not. We tend to want to say what others want to hear. I think we are still caught up in trying to please everybody. I think we should just stop and focus on working with those CSPs where it's working well (Regional Development Manager, England Basketball).

We like to present this idea that everything is rosy, everything is wonderful. We have to be more prepared to discuss the problems and the things that are not working as much as we do those things that are working well (County Director, England \& Wales Cricket Board).

Thus, the performance management process underpins two significant problems. First, it drives a focus on perception over reality, where the desire to present oneself in the best possible light prevails over honesty, which in turn influences the norms and culture of the policy sub-system. 
Gaming the system for the purpose of submitting an excellent report becomes standard practice. Second, and more important, the façade of 'excellence' inhibits the sharing of problems, mistakes and the more general policy learning that could emerge if a more genuine, democratic, and open epistemic community were to exist.

\section{Summary}

In this brief chapter we have attempted to highlight the value of a new approach to policy, 'new governmentality', in analyzing the governance context in which (sport) policy is made. We did so by drawing attention to the dominant position that the concept of 'governance' has taken in debates on government set policy delivery. Further, we introduced a new 'hard interpretivist' version of 'governmentality', which draws on the concept of governance, but focuses very much on the government's attempt to shape and guide agents' behaviour according to government wishes through - ostensibly - devolving and dispersing power downwards closer to where policy is implemented. Such an approach is essential, we believe, especially given the unquestioned nature of the system of governance in the majority of advanced capitalist states: New Managerialism. Finally, we went on to show - using an empirical example of UK community sport policy - how this is not just a lofty academic debate: such a system of governance has a real-life impact on how policy is delivered and implemented; it also impact greatly on the behaviour of the agents within the organisations and partnerships involved in delivering community sport policy. 


\section{References}

Barron, A. 2005. Foucault and Law in Introduction to Jurisprudence and Legal Theory: Commentary and Materials, edited by J. Penner, S. Schiff, and R. Nobles, 955-1034. Oxford: Oxford University Press.

Barrett, S \& Fudge, C. 1981. Policy and action. London: Methuen.

Bevir, M. \& Rhodes, R.A.W. 2006. Governance Stories. London: Routledge.

Bevir, M. and Rhodes, R.A.W. (2008) The differentiated polity as narrative, British Journal of Politics and International Relations, 10(4), 729-734.

Bloyce, D., Smith, A,. Mead, R, \& Morris, J. 2008. Playing the Game (Plan): A Figurational Analysis of Organizational Change in Sports Development in England. European Sport Management Quarterly, 8(4), 359-378.

Bulley, D. \& Sokhi-Bulley, B. 2014. Big Society as Big Government: Cameron’s Governmentality Agenda. The British Journal of Politics and International Relations, 16, 452-470.

Cameron, D. 2009. The Big Society, Hugo Young Lecture, 10 November, Available online at: http://www.theguardian.com/politics/video/2009/nov/10/david-cameron-hugo-young-lecture (Accessed November 12, 2015)

Coxall, B., Robins, L. \& Lynton, R.L. 2003. Contemporary British Politics. 4th Edition. London: Palgrave MacMillan.

Deming, W. E. 2000. Out of the Crisis. Cambridge. MA: MIT Press.

Department of Culture, Media and Sport. 2015. Report of Triennial Review of UK Sport and Sport England. London: DCMS.

Dorey, P. 2005. Policy Making in Britain: An Introduction. London: Sage.

Foucault, M., Burchell, G., Gordon, C., \& Miller, P. (1991). The Foucault effect: Studies in governmentality. University of Chicago Press.

Foucault, M. 2002. The Subject and Power, in Power: Essential Works of Foucault 1954-1984 (volume 3), edited by J. Faubion. Hammondsworth: Penguin. 
Goodwin, M. \& Grix, J. 2011. Bringing structures back in: The governance narrative, the Decentred Approach and Asymmetrical Network Governance in the education and sport policy communities, Public Administration, 89 (2), 537-556.

Gordon, C. 1991. Government Rationality: An Introduction in The Foucault Effect: Studies in Governmentality, edited by G. Burchell, C. Gordon and P. Miller. London: Harvester/Wheatsheaf. See above - Foucault 1991

Green, M. 2009. Podium or participation? Analysing policy priorities under changing modes of sport governance in the United Kingdom, International Journal of Sport Policy, 1(2), 121-144.

Green, M. \& Houlihan, B. 2006. Elite sport development policy learning and political priorities. London: Routledge.

Grix, J. (2009). The impact of UK sport policy on the governance of athletics. International journal of sport policy, 1(1), 31-49.

Grix, J. 2010. The Governance Debate and the Study of Sport Policy. International Journal of Sport Policy, 2(2), 159-171.

Grix, J. \& Phillpots, L. 2011. Revisiting the Governance Narrative: Asymmetrical Network Governance and the Deviant Case of the Sport Policy Sector. Public Policy and Administration, 26(1), 3-19.

Harris, S., 2013. An analysis of the significance of the relationship between NGBs and CSPs in the delivery of community sport policy. Thesis $(\mathrm{PhD})$. Loughborough University.

Hill, M. (2009) The public policy process (5th edition). Edinburgh: Longman

Houlihan \& Green. 2012. Routledge Handbook of Sport Development. London: Routledge.

Lipsky, M. 1980. Street level bureaucracy: dilemmas of the individual in public services. New York: Russell Sage Foundation.

Marsh, D. (2008a) Understanding British government: Analysing competing models, The British Journal of Politics \& International Relations, 10(2), 251-268. 
Marsh, D. (2008b) What is at stake?: A response to Bevir and Rhodes, The British Journal of Politics \& International Relations, 10(4), 735-739.

Marsh, D. \& Smith, M. 2000. Understanding policy networks: towards a dialectical approach. Political studies, 48, 4-21.

Newman, J. 2005. Remaking Governance: peoples, politics and the public sphere. Bristol: Policy Press.

Raco, M. \& Imrie, R. 2000. Governmentality and rights and responsibilities in urban policy. Environment and Planning, 32, 2187-2204.

Roche, M. 1993. 'Sport and Community: Rhetoric and Reality in the Development of British Sport Policy', in Sport, Culture and Politics, edited by J. Binfield \& J. Stevenson (Eds.). Sheffield: Sheffield Academic Press

Skelcher, C. 2000. Changing images of the State: Overloaded, hollowed-Out, congested. Public Policy and Administration. 15(3), 3-19.

Sport England. 2015. About us, Available online at: http://archive.sportengland.org/about_us/what_we_do.aspx (Accessed September 19, 2015).

Sam, M.P. (2009) The public management of sport: wicked problems, challenges and dilemmas, Public management review, 11(4), 499-514.

Rose, N., 1999. Powers of freedom: Reframing political thought. Cambridge: Cambridge University

Press.

Piggin, J. Jackson, S. \& Lewis, M. 2009. Knowledge, power and politics: Contesting 'evidencebased' national sport policy. International Review for the Sociology of Sport.44, 87-101.

Taylor, A. 2000. 'Hollowing Out or Filling In? Taskforces and the Management of Cross-cutting Issues in British Government', British Journal of Politics and International Relations, 2, 1, 46-71. 
Figure 1: Community sport policy structure
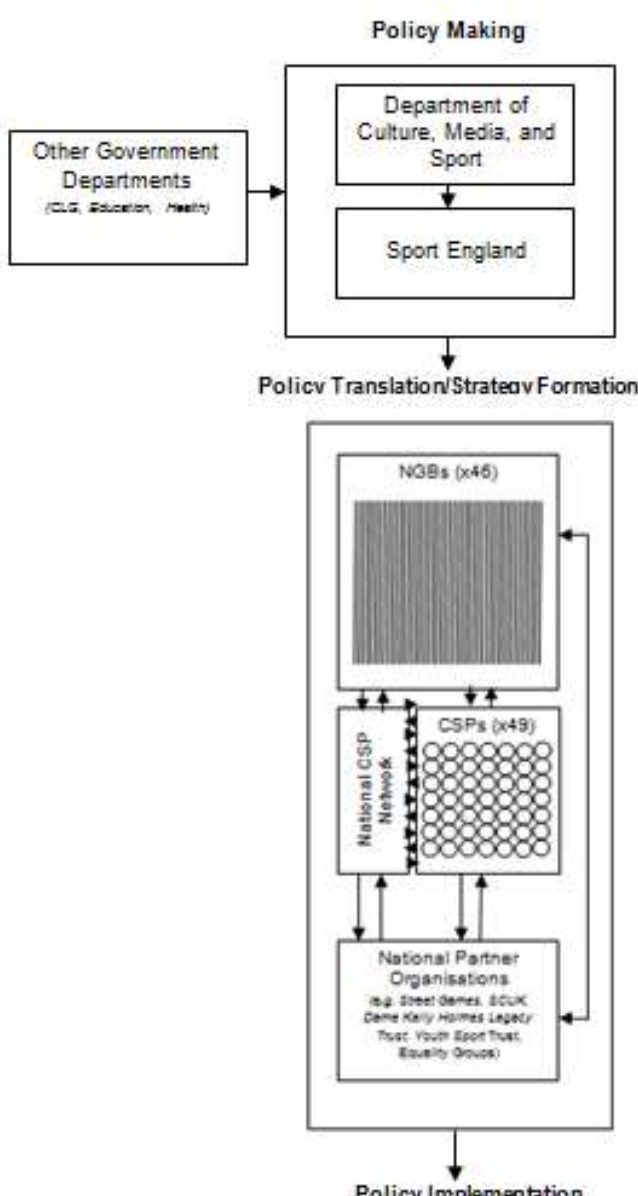

\begin{tabular}{|c|c|c|c|c|}
\hline NGes (arownat) & CSPs & vacs Coostes Clues & Coaches & $\begin{array}{l}\text { Non Sporting } \\
\text { Voluntary Sector }\end{array}$ \\
\hline Private Enterprise & $\begin{array}{l}\text { Higher \& Further } \\
\text { Education }\end{array}$ & Schools & Local Authorities & $\begin{array}{l}\text { National Partners } \\
\text { (sow Geman sove }\end{array}$ \\
\hline
\end{tabular}

